\title{
Searching for a Possible Relationship between Propensity to Savings and Rate of Profit
}

\author{
Mario De Marchi \\ Consiglio Nazionale Delle Ricerche, Istituto di Ricerca Sulla Crescita Economica Sostenibile (CNR-IRCRES), Roma, Italy \\ Email: mario.demarchi@hotmail.com
}

How to cite this paper: De Marchi, M (2020). Searching for a Possible Relationship between Propensity to Savings and Rate of Profit. American Journal of Industrial and Business Management, 10, 13361339.

https://doi.org/10.4236/ajibm.2020.108088

Received: June 20, 2020

Accepted: August 10, 2020

Published: August 13, 2020

Copyright () 2020 by author(s) and Scientific Research Publishing Inc. This work is licensed under the Creative Commons Attribution-NonCommercial International License (CC BY-NC 4.0). http://creativecommons.org/licenses/by-nc/4.0/

\begin{abstract}
This article is the follow-up of a research work about the foundations of the classical approach to the study of prices and income distribution. The author resumes an old idea put forward by A. Smith, but later rejected by the mainstream analysis. He then examines a link arising among crucial economic variables when the Classical and Keynesian perspectives are merged.
\end{abstract}

\section{Keywords}

Methodology of Economics, Theory of Prices and Income Distribution

\section{An Alternative Point of View within the Classical Perspective}

In a recent article (De Marchi, 2019), an ancient approach proposed by A. Smith (1994) was resumed, in order to develop a novel point of view, within the Classical perspective for an economic theory simultaneously determining income distribution and prices. The approach, revised in modern terms, consists in entirely reducing the price of a certain commodity to the incomes paid for its production. This way the particular commodity's value results to be independent of prices. As a consequence, that value can be used as an ideal measure of all other values. Usually, a complete reduction of any commodity's price entails an endless sequence of steps, because residual of such progress diminishes in an irregular way. But, on the other hand, if the layers of means of production we encounter along the process vary according to a recursive ratio, then the total amount of the series can be worked out by a simple logical-mathematical operation-as it happens with Sraffa's Standard Commodity, the ingenuous tool suggested by the great economist as a theoretical instrument to solve the problem of the ideal unit of measure of value. 
Sraffa, indeed, in a sentence that has perhaps received less attention than deserved remarked that the crucial feature of the Standard Commodity was just the recursive nature of the proportion between next layers of means of production, being the homogeneity among product and means of productions a consequence not a cause of the recursive nature of the proportion (Sraffa, 1960).

\section{Reducing the Price of a Commodity into the Incomes Paid for Producing It}

Let us make the hypotheses that:

1) the wage $\langle\langle\omega\rangle\rangle$ be paid post factum;

2) the $\langle\langle\zeta\rangle\rangle$ value of the Standard Commodity can be worked out as the limit of a sum, defined by a geometrical series, in which $\langle\langle r\rangle\rangle$ is the rate of profit and " $1+R$ " is the recurrent proportion between product and means of production:

$$
V=w((1+r) /(1+R))^{0}+\cdots+w((1+r) /(1+R))^{n}+\cdots+
$$

where $V$ remains finite and positive provided that $r<R$ (namely, the rate of profit remains below its maximum, the net reproduction rate of the Standard Commodity), and equal to

$$
w(1 / 1-((1+r) /(1+R)))=w((1+R) /(R-r))
$$

The result of such peculiar reduction is a new original relationship between the rate of profit and the value of Standard Commodity.

$$
(1+R) /(R-r) w=V
$$

where by: if, say, $V$ increased from the minimum, viable level $((1+R) / R) w$ (corresponding to no profits and zero $r$ ) towards the infinity, then $r$ would grow towards a maximum $R$.

Following a suggestion by Sraffa, we can give such unit of value a more tangible content by dividing both terms of (1) by $w$ so that in Equation (2) in the second term we obtain the work which $V$ can pay for, namely, in the words of Smith, the work $V<<$ commands $>>$.

$$
(1+R) /(R-r)=V / w
$$

Having reached this preliminary theoretical result, one may be tempted to compare the classical perspective with the Keynesian one, provided some assumptions be made.

\section{Exploring a Possible Symmetry}

A straightforward path to compare the Keynesian and the Competition Classical approaches is to bring about a symmetry between the most significant and relevant aspect of both theoretical sets. This way, one could write down a System of formulae in which one included a Keynesian contribution, another represented the Classical perspective (according to the novel, Competition point of view) and finally a third one set up a clear relationship between the two analytical points of view. Given Equation (1), let us suppose for the sake of simplicity, that: a ho- 
mogenous commodity only is produced in the Economic system, so that the national income $\langle\langle Y\rangle\rangle$ consists only in a quantity of Standard Product $V$; and define as usually the investment as $\langle\langle I\rangle\rangle$ and the propensity to saving as $\langle\langle s\rangle\rangle$. We can write down the System of Equations $(\sigma \rho . \dot{1})$ :

$$
\begin{gathered}
((1+R) /(R-r))=V / w \\
I / s=Y \\
Y=V
\end{gathered}
$$

In it, the first formula expresses the value $V$ of the Standard Product; the second formula includes what many scholars consider the most original and illuminating of Keynes' contributions to Economic Theory: the concept of multiplier and its role in the determination of national income $Y$ (Keynes, 1997); finally, by stating the $\langle<(\sigma \rho .3)>>$ equivalence we are implying that:

$$
I / w=s((1+R) /(R-r))
$$

Equation (3) brings about a basic, neat and perhaps empirical testable analytical consequence: such formula expresses the hypothesis that an inverse relationship there exists between the rate of profit and the propensity to savings. Indeed, once determined as in the Keynes' analysis the values of wages and Investments, and taken $\mathrm{R}$ as given along with the technology as in Sraffa's scheme, in order to keep the balance between the two sides of the equation: as $r$ grew towards $\langle<R>>$, $s$ would have to fall from its virtual maximum, $<<$ one $\rangle>$, towards zero, and vice versa.

The value of this hypothesis, if it was validated, appears remarkable, whereas through it a connection could be established between the Classical explanation of income and the Keynesian mechanism for the determination of effectual demand, whereby both approaches could supplement each other independently from the Marginalist theory.

\section{Acknowledgements}

The author is deeply indebted with two anonymous referees for their precious comments. However, the responsibility for the article's content remains with him.

\section{Conflicts of Interest}

The author declares no conflicts of interest regarding the publication of this paper.

\section{References}

De Marchi, M. (2019). Why A. Smith Might Have Been Right, After All. American Journal of Industrial and Business Management, 9, 1980-1982. https://doi.org/10.4236/ajibm.2019.911129

Keynes, J. M. (1997). The General Theory of Employment, Interest and Money. New York: Prometheus Books. 
Smith, A. (1994). The Wealth of Nations. New York: The Modern Library.

Sraffa, P. (1960). Production of Commodities by Means of Commodities. Cambridge: Cambridge University Press. 